\title{
Research on Urban Resilience Evaluation Model and Its Application in China
}

\author{
Ran Wei \\ School of Public Administration/Emergency Management, Jinan University, Guangzhou, China \\ Email:924803769@qq.com
}

How to cite this paper: Wei, R. (2020). Research on Urban Resilience Evaluation Model and Its Application in China. Open Journal of Social Sciences, 8, 407-416. https://doi.org/10.4236/jss.2020.83035

Received: March 6, 2020

Accepted: March 24, 2020

Published: March 27, 2020

Copyright $\odot 2020$ by author(s) and Scientific Research Publishing Inc. This work is licensed under the Creative Commons Attribution International License (CC BY 4.0).

http://creativecommons.org/licenses/by/4.0/

\begin{abstract}
Affected by the rapid progress of urbanization and the climatic environment, cities must continue to improve their resilience to enhance their "disaster-resistance" and "self-recovery" capabilities to cope with various types of disasters. Based on the urban resilience framework proposed by the Rockefeller Group, this study selected cities such as New York, New Orleans, Fukushima, Da Nang, and Athens as typical cases to analyze their resilience plans in detail, and discussed the construction of urban resilience evaluation models and their main impact factors, found that infrastructure resilience and social resilience are the two most important dimensions of urban resilience. At the same time, combined with the smart city index systems (standards) of Shanghai and Guangdong, China, to further optimize the evaluation model of urban resilience, and exploratively propose a set of urban resilience evaluation index systems suitable for urban applications in China.
\end{abstract}

\section{Keywords}

Urban Resilience, Infrastructure Resilience, Community Resilience, Community Resilience, Capital Resilience, Institutional Resilience, Environmental Resilience

\section{Introduction}

With the rapid economic development and population increase, the process of urbanization is also continuously moving forward, and it is putting great pressure on cities. The possibility of natural disasters is increasing due to the variability of the global environment and climate, such as the frequent occurrence of natural events such as earthquakes and water disasters, which continue to impact urban systems. There are many extreme events that will go beyond the scope of human knowledge and experience. Even developed countries with comprehensive disaster prevention and mitigation capabilities and emergency management ca- 
pabilities will inevitably cope with failure (IPCC, 2007).

The focus of urban resilience research is on how to improve the city's "preparation for disaster reduction" and "self-recovery". From a linguistic point of view, the word resilience comes from resilio in Latin, meaning to return to its original state. The term resilience appears in ecological science. It was originally proposed by Canadian ecologist Holling. According to this theory, the expression behavior of the ecosystem can be defined as two different attributes, resilience and stability. Toughness is divided into engineering toughness and ecological toughness. Smart city research includes the concept of resilience, one of the areas where cities can become smarter.

This study detailed and analyzed the resilience strategic plans of the five cities of New York, Toyama, Athens, New Orleans and Da Nang in the "100 Cities Resilience" project, and matched them with the city's resilience framework based on literature analysis. These five cities were chosen because: 1) The geographical distribution of these five cities is representative. 2) The disaster types and countermeasures in the five cities are beneficial. 3) The urban resilience systems of the five cities are systematic, large-scale, and sustainable. Our work will help establish a framework for understanding urban resilience, and provide a theoretical basis for better evaluation and improvement of urban resilience.

\section{Research Methods and Ideas}

First of all, through a large number of domestic and foreign urban resilience evaluation and related research literature, using theoretical analysis, frequency analysis, etc., collected six main aspects of urban resilience framework, namely social resilience, economic resilience, institutional resilience, infrastructure resilience, Community capital and environmental resilience, and the urban resilience model was constructed based on the relationship between the elements in the framework. Secondly, five participating cities in New York City, Toyama City, Athens City, Da Nang City, and New Orleans City were selected, and their strategic plans for urban resilience development were analyzed and arranged. And the status of smart city construction, the "Smart City Evaluation Index System" in Shanghai and Guangdong Province was selected as the reference basis for constructing the urban resilience framework. Finally, based on the analysis results of the above five cases, a process of optimizing and perfecting the urban resilience framework and model based on the theory was proposed, and a urban resilience framework and model more suitable for promotion and application in China was proposed.

\section{The Origin of "Urban Resilience" Theory and the Construction of Its Framework}

\subsection{Proposing Urban Resilience}

The combination of the theory of resilience and the discipline of disaster management has promoted the development of disaster management research, and 
then put forward the concept of urban resilience. Urban resilience is a new concept of urban governance that emerges after smart cities, and aims to improve the city's "disaster capacity" and "self-recovery capacity". The Resilience Alliance (2008) emphasizes that urban resilience means that cities can still maintain their original main features, structures, and key functions after being disturbed by the outside world. Alberti et al. (2003) pointed out that urban resilience is the ability and extent to absorb and resolve changes before the restructuring of urban structure changes. Mileti (1999) put forward the definition of local resilience, which specifically refers to the ability of local areas to ensure that the local area will not be damaged by catastrophic losses, normal productivity, and life can continue when disasters occur. Goldschalke \& Xu (2015) argue that urban resilience is composed of two parts: the physical system and the human community. The physical system includes natural and man-made environmental elements. It is like the bones and muscles of the urban system. The human community is the social and institutional component of the city. It is like the human brain that directs people's actions. Regarding the definition of urban resilience, although academics do not have a unified explanation, scholars have a more consistent understanding of urban resilience. They believe that urban resilience is the ability of cities to absorb and resolve shocks when they are exposed to external shocks. It can recover from the loss during the rescue.

\subsection{Urban Resilience Evaluation Framework}

Through the construction of urban resilience, the city's "disaster-resistance" and "self-recovery" capabilities will be improved to maintain a balanced urban ecosystem. This is a relatively stable state in the current urban development. Therefore, the construction of urban resilience is very necessary, and the construction of urban resilience is inseparable from the construction of its evaluation framework. The evaluation dimension of urban resilience comes from the connotation of urban resilience, and scholars have different understandings of the connotation of urban resilience.

After searching and collating the previous literature on urban resilience evaluation dimensions, 16 English literatures focusing on urban resilience framework and index system and 2 Chinese papers focusing on resilience and flexible urban framework were selected. We summarize the classification of the mainstream dimensions mentioned in these 18 documents and combine the previous summary of the connotation of urban resilience to divide the indicators of urban resilience into six areas: social resilience, economic resilience, community capital, institutional resilience, and infrastructure resilience and environmental resilience. The first-level dimensions of the urban resilience framework are social, economic, institutional, infrastructure, community capital, and environmental systems. The social and economic dimensions are two essential dimensions of urban resilience that are highly respected in the theoretical world; their importance in the theoretical world is second only to social and economic resilience; 
secondly, the importance of community capital is slightly lower than institutional resilience and infrastructure resilience, which is much lower than social and economic resilience. Finally, environmental resilience is less important in the theoretical world than all the other resilience dimensions, but in the international context of global warming and sustainable development, the environmental resilience dimension still essential.

Social resilience is a function that involves demographic characteristics and people's ability to acquire resources; economic resilience refers to the economic vitality of a local community and the diversity of the economic environment, which can ultimately be attributed to ensuring the stability of residents' livelihoods; institutional resilience refers to the The region has extensive disaster experience, disaster reduction planning and resources, including local government efforts to increase disaster awareness and residents' disaster preparedness; infrastructure resilience refers to the ability of a community to recover from and respond to disasters and infrastructure damage, For example, electricity, water supply, sanitation environment, and transportation network; community capital refers to the relationship between individuals and their neighborhoods; and environmental resilience refers to the frequency and intensity of disasters, the management of ecosystems, and sustainable Development and resource protection.

\section{Comparative Analysis of Urban Resilience at Home and Abroad}

\subsection{New York City}

New York City is located at the Hudson River estuary, with an overall area of about 468.9 square miles (1214 square kilometers). It has more than 520 miles of coastline and 8.4 million residents (in 2015), nearly 400,000 of whom live in buildings vulnerable to coastal flooding and rising sea levels. It is also threatened by a variety of natural disasters, including blizzards, hurricanes, floods and earthquakes.

In 2015, NYC implemented a resilience plan, which mainly contains four visions of building a dynamic New York City. They are Prosperous Cities, Fair and Just Cities, Sustainable Cities and Resilient Cities. The four visions of the New York Resilience Program include 24 goals, including seven target distribution in social toughness dimension, two construction targets distribution in economic resilience, distribution toughness of three in the system, and distribution in infrastructure toughness of latitude that most reached 10. Community capital and environmental resilience have 5 and 4 goals respectively. Obviously, in order of importance in New York's resilience plan, are infrastructure resilience, social resilience, community capital, environmental resilience, institutional resilience and economic resilience.

\subsection{Athens}

Athens is the capital of Greece with a history of more than 3000 years. As of 
2013, Athens had a population of 5 million and a total urban area of $412 \mathrm{~km}^{2}$. In recent years, Greece has faced severe economic challenges and continued environmental pressures. The main challenges fall into eight categories: earthquakes, climate change, civil strife, cybercrime, a depressed economy, aging infrastructure, migration, and mistrust. Athens' resilience plan has four components: 1) Effective and efficient governance, and better communication and collaboration with residents by promoting data-driven policy development and accountability. 2) Meet the human need to be close to nature and be able to resist climate change and environmental challenges. 3) Improve best "survival" skills and create a reliable and safe environment for people. 4) Nurture and develop their assets to promote happiness, creativity, and entrepreneurship.

Under the four directions of the Athens resilience plan, there are a total of 13 measures. Institutional resilience is one of the dimensions that have received the most attention in the Athens resilience strategic plan. The second focus is on social resilience, with eight targets distributed, infrastructure resilience and community capital supported by seven specific measures. Last in line is environmental resilience and economic resilience. In terms of quantity, economic resilience receives far less attention than other dimensions, but in terms of content, it receives more attention.

\subsection{Toyama}

Toyama belongs to Japan, with an area of 1242 square kilometers and a large amount of agricultural land. Its total population is about 420,000 (in 2010). The challenges facing toyama can be summed up in two categories: acute shock and chronic stress. Acute shock has four main types of acute shocks: floods, landslides, earthquakes and potential infrastructure failures. There are five main types of chronic stress: aging and declining populations, aging infrastructure, a lack of economic resilience, environmental degradation and inadequate opportunities for residents to achieve self-actualisation goals. Toyama, Japan, developed and released its resilience planning strategy on July 12,2017 , which sets building targets that will last until 2050. The idea of fushan resilience planning strategy is based on four aspects: Resilient People, Resilient Prosperity, Resilient Infrastructure and Resilient Environment. These four aspects contain 10 specific goals. According to the six dimensions of the urban resilience framework, infrastructure resilience and economic resilience are given enough attention in the Toyama resilience plan, nine of the ten targets are related to them. Then there's social resilience and environmental resilience, which have six goals, community capital, institutional resilience are last.

\subsection{Da Nang}

Danang is a coastal city and one of the five most prosperous cities in Vietnam. It is located in central Vietnam. It has an area of $1285.4 \mathrm{~km}^{2}$. Resilience strategies are in four areas: health and happiness; economy and society; infrastructure and 
environment; leadership and strategy (2017). A total of 36 actions are in $\mathrm{Da}$ Nang, of which 5 actions are distributed in social resilience, 6 actions are distributed in economic resilience, 15 actions are distributed in institutional resilience, 13 actions are distributed in infrastructure resilience and 5 behaviors are distributed in community capital, and the four behaviors are distributed in a resilient environment. Based on these data, we can conclude that the proportion of each dimension of the Danang Resilience Plan is $10.4 \%, 12.5 \%, 31.3 \%, 27 \%$, $10.4 \%$ and $8.3 \%$. Institutional resilience, infrastructure resilience, economic resilience, community capital, social resilience, and environmental resilience are in order of importance. The biggest concern is infrastructure and institutional resilience. The resilience strategy is an initial plan, and there is still a certain distance from specific actions. Therefore, institutional resilience is welcome in this plan. In addition, Da Nang is a coastal city that faces natural disasters such as floods and storms, and infrastructure construction is a direct tool to withstand storms.

\subsection{New Orleans}

New Orleans is a seaport city in southern Louisiana. New Orleans plans: Be resilient New Orleans in 2015. They consist of three visions: 1) adapting to prosperity, meaning cities embrace a changing environment; 2) connecting opportunities, we are a fair city; 3 ) changing urban systems, we are a vibrant and prepared Cities (2017). The plan has 16 goals.

Similar to New York, some goals belong to multiple dimensions. From the perspective of dimensions, we can find that there are 3 targets distributed in the social dimension, and 2 targets distributed in economic resilience, 5 targets distributed in institutional resilience, 6 targets distributed in infrastructure, and 2 targets distributed in community capital. And 4 targets are distributed in environmental toughness. We can calculate the percentage of each dimension is $13.6 \%, 9.1 \%, 22.7 \%, 27.2 \%, 9.1 \%, 18.2 \%$. The results show that infrastructure resilience is the most popular in the New Orleans Resilience Plan, followed by institutional resilience. This is followed by environmental resilience and social resilience, with economic resilience and community capital receiving equal attention. In short, institutional resilience and infrastructure resilience are more valuable in New Orleans. Because New Orleans is a coastal city and faces various weather disasters, it mainly relies on infrastructure such as dykes to prevent coastal disasters.

\subsection{China Smart City}

China's five cities are undergoing urban resilience construction, namely Chengdu, Deyang, Huangshi, Yiwu and Haiyan. Among them, Chengdu participated in the "Making Cities Resilient" campaign organized by the United Nations Disaster Reduction Agency in 2011, and also established the "Chengdu Declaration of Action". However, the current data on urban resilience is limited, and China's 
research and practice in the field of smart cities has been practiced for a long time. Some cities have even established local standards for smart cities, such as Guangdong and Shanghai. The smart city index book of Guangdong Province and Shanghai is selected here as a reference for the urban resilience framework, with the aim of drawing some inspiration from it.

The Shanghai Pudong New Area released the "Smart City Index System 1.0" in 2011. The determination of relevant indicators is based on the following principles: 1) collectability 2) representativeness 3 ) comparability 4) scalability. The "Smart City Index System" is mainly divided into three levels: first-level indicators, second-level indicators, and third-level indicators. The first-level indicators are mainly carried out from the following five aspects: infrastructure, public management and services, economic development of information services, humanities literacy, and perception of the city's democratic outlook. There are 19 secondary indicators and 64 tertiary indicators.

The Guangdong Provincial Bureau of Quality and Technical Supervision issued the local standard of the "Smart City Evaluation Index System" (DB44/T 1957-2016) in December 2016, which was implemented in mid-March 2017. This indicator system consists of three levels, four first-level indicators, ten second-level indicators, and three third-level indicators, and the weights of each level are given. The weight of smart city infrastructure in this indicator system is $31 \%$, and the weight of the four first-level indicators is the most important, indicating that it is the most valued, which coincides with the original concept of smart cities.

\section{Optimization of Urban Resilience Frame Model}

The urban resilience framework for the city level was extracted from the literature review, and finally, the urban resilience model was established, which briefly showed the elements of the urban resilience framework and their relationships. The content of urban resilience construction has certain differences. As shown in Figure 1, it is a comprehensive distribution of the resilience of the five cities.

It can be seen from the figure that the distribution of New York City is mainly concentrated on infrastructure resilience and social resilience, followed by community capital and environmental resilience, and finally system resilience and economic resilience. Obviously, such distribution characteristics are not the same as the degree of importance at the theoretical level. Most scholars emphasize that social resilience and economic resilience are stronger than infrastructure resilience and institutional resilience. Not only does New York's attention on the six dimensions differ from theoretical results, the distribution of goals in Toyama and Athens also reflects their respective characteristics. Toyama City attaches the greatest importance to economic resilience, followed by infrastructure resilience, social resilience, Environmental resilience, community capital, and institutional resilience; the distribution characteristics of Athens are institutional resilience, social resilience, infrastructure resilience, community capital, environ- 
mental resilience, and economic resilience; Da Nang's distribution characteristics are institutional resilience, infrastructure resilience, and economic resilience Social resilience is important to community capital resilience, and finally environmental resilience. The distribution characteristics of New Orleans are that infrastructure resilience, institutional resilience, social resilience, and community capital resilience are important to economic resilience, and finally environmental resilience. These results may vary from country to country, or from city to city and geographical differences.

As shown in Figure 2, it integrates the resilience goals of the five cities. It is found that the number of target support in the six dimensions of the urban

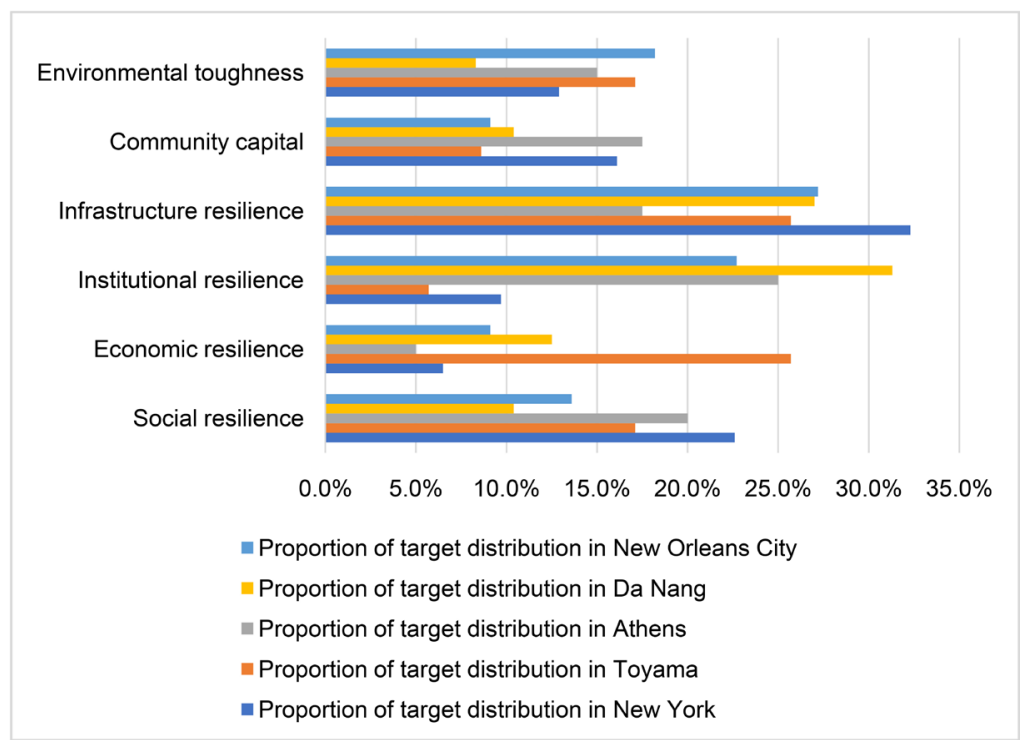

Figure 1. Distribution of resilience targets in five foreign cities on the resilience index system.

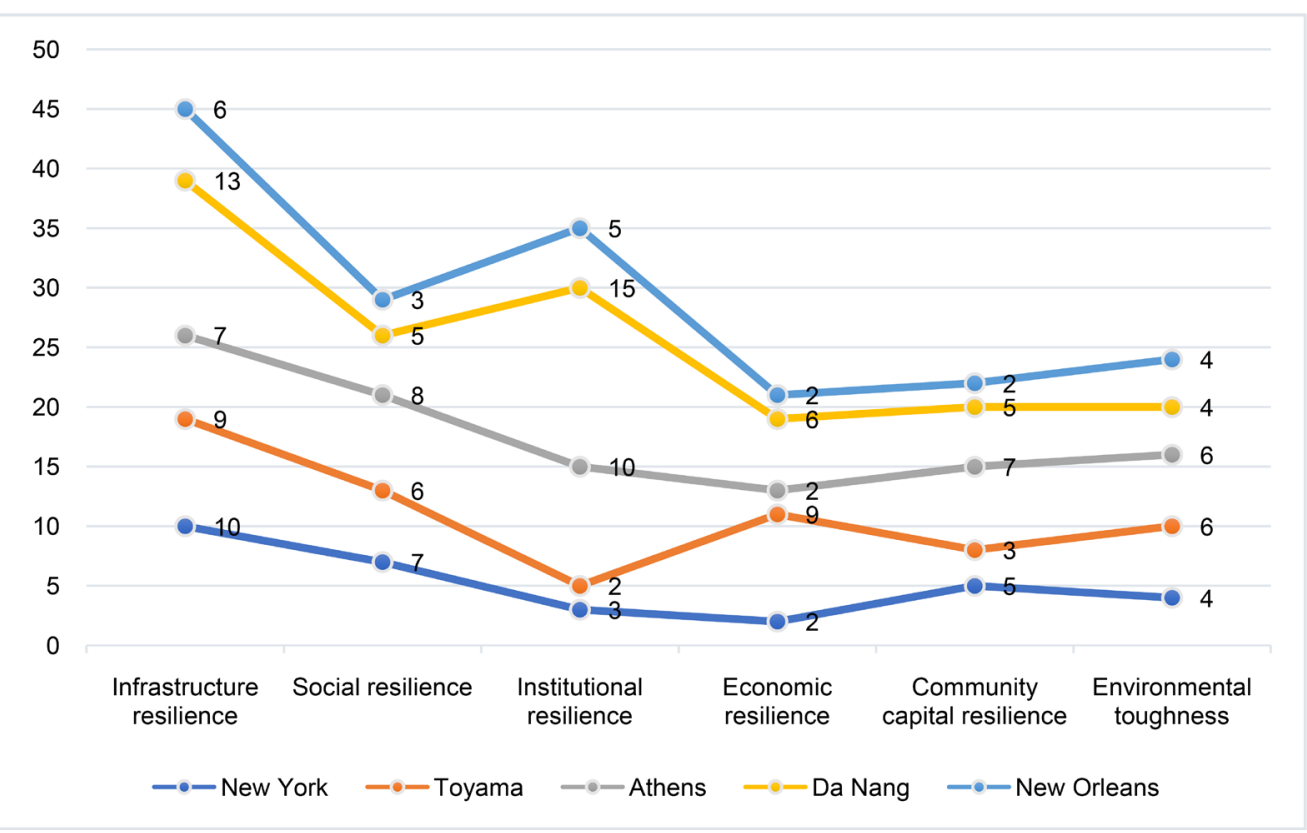

Figure 2. Six dimensions of the five cities' urban resilience framework and their target support numbers. 
resilience framework is infrastructure resilience (45), institutional resilience (35), and social resilience (29), Economic resilience (21), community capital (22), and environmental resilience (24). The above conclusions are not the same as the order of importance of the six dimensions obtained in theory. Infrastructure resilience is the most concerned construction content in practice; the second is institutional resilience; the third is social resilience; the fourth is environmental resilience; the fifth is social capital resilience, indicating that it has received attention in practice and Not much; the last one is economic resilience, which focuses on the least dimension in the process of urban resilience construction.

On the basis of previous studies, an optimized urban resilience model is proposed based on practical application effects. Compared with the theoretical urban resilience model, it is mainly reflected in the order of importance. By analyzing the "smart city evaluation index system" of Guangdong Province and Shanghai, it was found that Guangdong Province mainly mentioned four aspects of smart city infrastructure, economic development, social life, and government management and services, while Shanghai mentioned infrastructure, Economic development, humanities literacy, public management and services, and these aspects can be summarized as infrastructure, economic, social, and institutional aspects. Guangdong Province has also given weight to these four aspects. The weights are ranked as follows: infrastructure (31\%), economic development (24\%), social life (24\%), government management and services (21\%). Based on the above, it can be seen that the focus of urban resilience and smart cities are different. For example, less attention is paid to economic resilience in the process of urban resilience construction, while the construction process of smart cities places the importance of economic development and social life second. This study takes three major foreign cases as the main body of reference, and the smart city indicator systems in the two major domestic regions as a reference.

\section{Conclusion}

There is a potential mismatch between the conceptual and practical methods of resilience. Although the conceptual perspective is exhaustive in describing the categories and subcategories of urban resilience, practice has shown that change may respond to the contextual differences and goals of each city. Any measurement framework should consider these contextual differences. This process will result in better resilience measures and may draw policy makers' attention to issues that are not considered in the plan but are important, such as education and equity, public health services and social services and benefits, economic diversity, employment and the economy recovery. In addition, both the state's ongoing administrative approval and decentralization have emphasized the key role of grassroots organizations. The optimized urban resilience framework and model not only include the four aspects emphasized by smart cities, but also place the grass-roots organization of the environment and community in a more important position. Therefore, urban resilience can better guide society Development 
is also more in line with the law of social development, and China should upgrade urban construction to urban resilience construction on the basis of smart city construction as soon as possible.

\section{Conflicts of Interest}

The author declares no conflicts of interest regarding the publication of this paper.

\section{References}

Alberti, M., Marzluff, J., Shulenberger, E. et al. (2003). Integrating Humans into Ecosystems: Opportunities and Challenges for Urban Ecology. BioScience, 53, 1169-1179. https://doi.org/10.1641/0006-3568(2003)053[1169:IHIEOA]2.0.CO;2

Goldschalke, D. R., \& Xu, Y. (2015). Urban Disaster Reduction: Creating Urban Resilience. International Urban Planning, 30, 22-29.

IPCC (2007). The Forth Assessment Report of the IPCC.

Mileti, D. (1999). Disasters by Design: A Reassessment of Natural Hazards in the United States. Washington DC: Joseph Henry Press.

Resilience Alliance (2008). Urban Resilience Research Prospectus. 